\section{Birdlife down on the farm}

\section{John Andrews}

Farming and Birds. By Raymond J. O'Connor and Michael Shrubb. Cambridge University Press: 1986. Pp.290. $£ 17.50, \$ 34.50$.

FARMING is the main agent of the destruction of terrestrial wildlife habitats throughout the world. Sometimes the process is quick and obvious, such as the clearance of forest or the drainage of wetland. Often it is gradual and imperceptible, for instance where domestic livestock introduced to natural grassland graze-out the palatable vegetation. At the same time, there have always been species with adaptations suited to the new circumstances and with the powers of dispersal necessary for colonization. Some birds have altered their world ranges in response to opportunities created by agriculture, many have increased in abundance and a few become economically significant pests. Where the entire land surface is man-modified, farms may retain semi-natural areas which are little used and remain relatively species-rich, while the farming system itself may sustain most

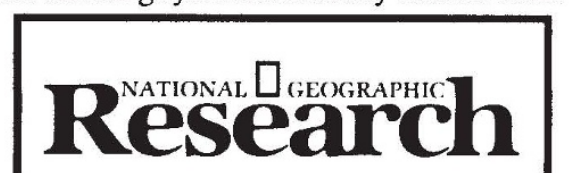

\section{a quarterly scientific journal for scientists, students, researchers. . .}

Written and edited by scientists, it offers multidisciplinary coverage

in fields such as anthropology, ecology, geography, and zoology. It features:

- original manuscripts, peer review

- technical detail, color graphics

- indexing by major services

- open submissions policy

- book reviews, letters, and more.

\section{Just \$40*}

for an annual subscription in the U.S Reader Service No.1

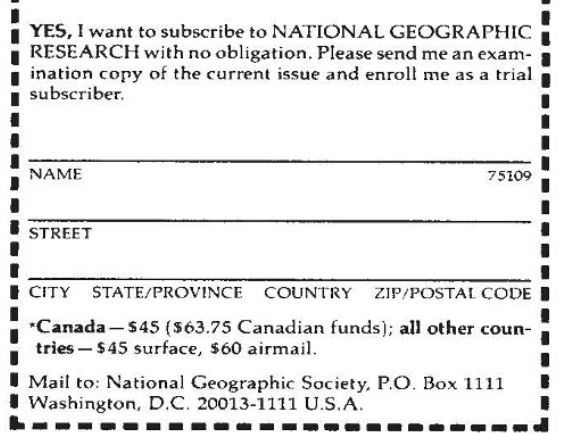

Mechanization and chemical technoloor all of the populations of some species grey partridge, rook and whitethroat in Western Europe, for example.

In both Europe and the United States the future of agriculture is unclear, mainly because of over-production, and conservation bodies that wish to influence that future must understand and be able to demonstrate the ecological effects of different farming practices. The publication of Farming and Birds is therefore most timely, particularly because it is, perhaps surprisingly, the first systematic attempt to review knowledge of the impact of British agriculture on the country's birdlife. It confirms the subjective view of many naturalists that recent changes in practice have been generally detrimental to birds and hoists a warning flag over the future of several species. Moreover, its broad findings probably have relevance in all countries with technically advanced agriculture.

The senior author, Raymond O'Connor, is director of the British Trust for Ornithology (BTO) which has built up data on bird population changes for over 25 years, mostly in the form of systematic observations made by hundreds of skilled amateurs. Michael Shrubb is one such amateur and, more importantly, a farmer with a wide understanding of agricultural systems. They have drawn on four sources of data - the BTO's Common Birds Census and Nest Record Scheme, including much previously unanalysed material; the existing literature, some of it unpublished; the Ministry of Agriculture's annual farm census returns which show changes in cropping patterns; and surveys of fertilizer usage. The volume of data available was such that a 1980 cut-off date was applied.

Farming is a dynamic activity and the authors commence by summarizing its history from the Middle Ages to the Second World War, showing how patterns of grass cover and tillage change in response to economic forces. Next they describe Britain's farmland bird community, which has always been small in terms of numbers of species. The original climax vegetation being woodland, Britain has few birds adapted to life in open fields, unlike North America for instance. At the core of the farm avifauna are woodland birds which use hedges, farm woods and farmstead gardens for nesting and for much of their foraging. Their overall distribution is determined by climate, soil type and terrain, both directly and indirectly through the influence of these factors on farming procedures. The value of farmland as nesting and foraging habitat is assessed in relation to performance in primary habitats and in different farming contexts. The authors conclude that mixed farming systems, combining tillage crops and livestock within holdings averaging about 25 hectares, are most favourable to bird diversity and abundance. gy increasingly permit specialization and intensification in agriculture, and the effects on birdlife are considerable. A number of them are considered, including the loss of feeding opportunities associated with the reduction in the number of mixed farms; the removal of features such as hedges and ponds; the intensification of use of semi-natural farmland (such as the conversion of old permanent pasture);
Not sitting pretty - the lapwing (Vanellus vanellus), which is under threat from new farming practices in certain regions of Britain.

changes in the timing of cropping, including the shift to autumn-sown cereals; and the use of pesticides and artificial fertilizers. Several birds, common until recently, including linnet, grey partridge and lapwing, are seen as being at risk of extinction in certain regions.

The book is open to criticism on several counts. There are some dangerous simplifications, such as the statement that "wildlife can adapt to change and has done so in the past but it cannot keep pace with the speed of modern technological development". A number of conclusions are tentative, because data are incomplete, or have been inferred from the fact that changes in bird numbers or distribution coincide with change in farming practice. And some studies by other workers appear to be accepted uncritically. The fact is, as the authors themselves state that knowledge of the effects of farming operations on birds is still very limited and the ecology of farmland species is understood only poorly. Nonetheless this is a valuable exercise, readable if somewhat repetitious, with many pointers for further study in Britain and elsewhere.

John Andrews is Chief Advisory Officer for The Royal Society for the Protection of Birds, The Lodge, Sandy, Bedfordshire SG192DL, UK. 